\title{
Eponymous verb phrases and ambiguity resolution
}

\author{
DAVID N. RAPP and RICHARD J. GERRIG \\ State University of New York, Stony Brook, New York
}

\begin{abstract}
To understand eponymous verb phrases such as "do a John Travolta," readers cannot merely select a sense out of a mental lexicon (sense selection). They must create new senses (sense creation) by retrieving salient information from memory. We conducted two experiments to test the hypothesis that these processes of memory retrieval parallel those used for ordinary lexical ambiguities. To prepare for Experiment 1, we gathered readers' interpretations of eponymous verb phrases like "do a John Travolta" to establish dominant and subordinate interpretations. We then wrote story contexts that biased comprehension toward one or the other interpretation. In Experiment 1, paraphrase judgment times were used to demonstrate that dominant meanings are privileged in the sense that they are accessible even when the story creates a subordinate bias. In Experiment 2, this privilege faded somewhat when there was a delay before the paraphrase judgment. We discuss the results with respect to the distinction between sense selection and sense creation.
\end{abstract}

When alternative rock star Beck was asked by Rolling Stone magazine to comment on his rise to fame he replied, "When I come out in a fringe Nudie rhinestone suit, people immediately say, 'Oh, he's doing an Elvis.' I mean, how simple-minded can you be?" says Beck. "It's like, pick up a harmonica, and you're 'doing a Dylan."' The expressions "doing an Elvis" and "doing a Dylan" are eponymous verb phrases, verb phrases based on salient acts of the eponyms (H. H. Clark \& Gerrig, 1983). Eponymous verb phrases are one of several categories of contextual expressions (E. V. Clark \& H. H. Clark, 1979; H. H. Clark, 1983). By definition, contextual expressions can take on an unlimited number of senses in an unlimited number of discourse contexts. For example, in appropriate contexts, "doing a Dylan" could mean "playing a harmonica," "winning a Grammy at an advanced age," or "changing from an acoustic to an electric guitar."

The unlimited ambiguity of contextual expressions contrasts with the more modest ambiguity of conventional expressions such as bank or cast. To capture this contrast, H. H. Clark and Gerrig (1983) suggested that contextual expressions require processes of sense creation - processes that allow discourse contexts to constrain nonlexical information retrieved from memory - that are different from the processes of sense selection - processes that, for example, enable readers to select the "bone mender" or "participants in a performance" sense of cast from the mental lexicon in appropriate contexts. Most analyses of the pro-

We thank Susan Brennan, Emily Durbin, James Polichak, Arthur Samuel, and Greg Simpson for stimulating comments on earlier versions of this manuscript. We also thank Norbert Gershkovich and Dimitrios Magiasis for assistance in data collection. Please address all correspondence to D. N. Rapp, Department of Psychology, State University of New York, Stony Brook, NY 11794-2500 (e-mail: drapp@psych1. psy.sunysb.edu). cesses of sense creation and sense selection have treated them as cases apart. On the sense creation side, researchers have typically considered individual types of contextual expressions such as eponymous verb phrases $(\mathrm{H}$. H. Clark \& Gerrig, 1983; Zelinski \& Hyde, 1996), denominal verbs (E. V. Clark \& H. H. Clark, 1979), and compound nouns (e.g., Gagné \& Shoben, 1997; Gerrig, 1989; Gerrig \& Murphy, 1992; Wisniewski, 1997) without making any particular claims about the relationships between processes of selection and creation. On the sense selection side, researchers typically overlook sense creation entirely (e.g., Simpson, 1994). In doing so, they fail to draw out the importance of sense creation for a wholly adequate account of meaning recovery (cf. H. H. Clark, 1997; Gerrig, 1986). In this project, our goal was to use eponymous verb phrases as a means to scrutinize the distinction between sense selection and sense creation.

As with all contextual expressions, there is no formal limit on the potential meanings of eponymous verb phrases. In practice, however, the interpretation of an eponymous verb phrase depends on salient acts associated with the eponym (H. H. Clark \& Gerrig, 1983). These salient acts are typically few in number, and they may change over time. We see in Table 1, for example, interpretations of "do an O.J." ( $5 \mathrm{a}$ and $5 \mathrm{~b}$ ) that are radically different from what that phrase might have evoked several years ago. Because interpretations rely on salience, it seems likely that at any given time an eponymous verb phrase based on a wellknown name will have a dominant interpretation, in the absence of discourse context. For eponyms with diverse accomplishments, it also seems likely that the verb phrases will have several subordinate readings. For example, the dominant interpretation of "do an Albert Einstein" might be "behave like a genius"; subordinate interpretations might be "have unkempt hair" or "move to Princeton, New Jersey." 
Table 1

Eponymous Verb Phrases

1. 'When I come out in a fringe Nudie rhinestone suit, people immediately say, ' $\mathrm{Oh}$, he's doing an Elvis.' mean, how simple-minded can you be?" says Beck. "It's like, pick up a harmonica, and you're 'doing a Dylan."”

(Magazine interview with the musician Beck.)

2. "I had thought, everyone knows I'm a man of a certain age. Now that I'm playing a woman, they'll put gauze over the lens. They'll do a Marlene Dietrich to me, make me look terrific."

(Actor Terrence Stamp; magazine article about "Priscilla, Queen of the Desert.")

3. [Sylvester] Stallone is taking a big chance here, and it is widely seen as an attempt to perform a Bruce Willis - that is, to shore up a flagging action career by doing something serious.

(Magazine article about Stallone's participation in the movie "Cop Land.")

4. Colette did an Ottoline, returning to his bed to fill it when it was empty of Dora.

(Magazine article about Bertrand Russell. Ottoline was Russell's intermittent lover, providing succor around several other affairs.)

5a. A coinage has forged itself within the media community of the West Coast: "O.J.," as a verb. Thus, "to O.J." Or, passively (and much, much more commonly), "to be O.J.-ed" or "to get O.J.-ed." "O.J.-ing," generally, has nothing to do with sports or movies, or sexual jealousy. It has to do with media reschedulings caused by extra coverage of the O. J. Simpson trial.

"People are always getting O.J.-ed off of things," explains Kathi Goldmark, my media escort in San Francisco.

"So for example you'd say. . .?"

“"Norman Mailer was going to do national TV, but he got O.J.-ed off of it."

I glance at my schedule and say, "Look! I'm meant to do a radio interview at eleven-thirty. Live. But it says here they'll tape it if I get O.J.-ed."

(Magazine essay by Martin Amis.)

5b. Martin Amis...notes that in Los Angeles "O.J." has become a verb. . . . In New Jersey, this verb has a different meaning. Recently, I was standing in line at a local deli behind a customer who asked the counterman to "O.J." his sandwich. Without a word of inquiry, the employee lifted his knife and cut the sandwich in half.

(Letter in response to original essay.)

6. No young New York actor has yet done a Johnny Depp and opened a club like the Viper Room as a nighttime sanctuary for the conspicuously hip.

(Magazine article)

7. [Green Lantern is feeling frustrated while patrolling the city streets.]

Green Lantern: "Rats! I finally get Dr. Light on the ropes-and he manages to pull a Houdini on me!"

(Comic book)

8. Boopsie: I'm sorry, B.D., but I don't want to move! My Malibu life is my all-time favorite.

B.D.: Boopsie, some of us only have one life! Why can't you just pull a Travolta and be reborn as a star in another lifetime?

(Comic strip)

9. My wife just pulled an Anna Karenina on me

(Cartoon punchline. Presumably "pulled an Anna Karenina" means "ran off with another man" rather than "threw herself in front of a train.")

10. And, moving across to Versailles Villa, here is Mrs. Dubash with her shrine to the god Ganesh, stuck in the corner of an apartment of such supernatural untidiness that, in our house, the word "dubash" became a verb meaning "to make a mess"... "Oh, Saleem you've dubashed your room again, . . ." Mary would cry. (Salman Rushdie, Midnight's Children)

Note-Many eponymous phrases are formed with "perform a" or "pull a" rather than "do a"; others may be formed with the bare eponym as the verb phrase (e.g., Example 10).

We invoke the concepts of dominant and subordinate interpretations to create a parallel with theoretical analyses of ordinary lexical ambiguities. Consider the word bank, which has as its dominant meaning "a financial institution" and as its subordinate meaning "the side of a river" (Onifer \& Swinney, 1981). Under what discourse circumstances are one or both of these meanings accessible during moment-by-moment comprehension? Research on the resolution of lexical ambiguities has focused on processing differences for dominant and subordinate meanings (for a review, see Simpson, 1994). One relevant finding is that the dominant meaning is privileged with respect to the subordinate meaning. Tabossi and Zardon (1993) wrote sentences that created biases toward the dominant and subordinate readings of ambiguous words. Using a cross-modal lexical decision task, they demonstrated priming for the dominant meaning irrespective of context, but priming for the subordinate meaning only when the context was specifically biased toward that reading. Research on lexical ambiguities also suggests that, over time, the 
privilege for dominant meanings fades. For example, Paul, Kellas, Martin, and M. B. Clark (1991) used a Stroop paradigm to show color-naming interference for dominant meanings in subordinate contexts when the test word appeared immediately at the offset of the ambiguity (i.e., at a 0 -msec interstimulus interval [ISI]). This interference diminished at longer ISIs ( 300 and $600 \mathrm{msec}$ ).

The present experiments were intended to generalize these results from ordinary lexical ambiguities to one type of contextual expression. That is, we used eponymous verb phrases to demonstrate the generality of the memory processes that yield this distinctive pattern of results for dominant and subordinate interpretations. We conducted preliminary norming studies designed to identify and verify dominant and subordinate interpretations of a pool of eponymous verb phrases. Then, in Experiment 1, readers read stories that created biases toward the dominant or subordinate interpretations of the eponymous verb phrases and subsequently agreed or disagreed with paraphrases that represented one of the two readings. In Experiment 2 , readers also provided agreement judgments, but these judgments were delayed by a sentence after the eponymous verb phrase. Our experiments support the generality of dominance effects.

\section{EXPERIMENT 1}

We designed Experiment 1 to demonstrate that dominant meanings of eponymous verb phrases experience the same privilege as do those for ordinary lexical ambiguities. In this experiment, participants read stories that instantiated dominant and subordinate contexts for eponymous verb phrases (for examples, see Table 2). The participants read the stories on a computer and then indicated their agreement or disagreement with paraphrases as swiftly as possible. We made a pair of predictions for "agree" (i.e., with the paraphrase) and "disagree" responses.

1. Readers should provide "agree" responses when there is a match between the contextual bias and the interpretation. In parallel to studies on lexical ambiguity, we predicted that "agree" responses would take roughly the same amount of time for both dominant and subordinate contexts. This first prediction reflected the equal accessibility of dominant and subordinate meanings in congruent contexts.

2. Readers should provide "disagree" responses when there is a mismatch. Again in parallel to studies on lexical ambiguity, we expected participants to reject subordinate paraphrases quickly when they occurred after dominant contexts in comparison with dominant paraphrases following subordinate contexts. If it is the case, that is, that the dominant reading is accessed, irrespective of context, participants should have difficulty ruling it out even in the subordinate context. This second prediction reflected the hypothesis that dominant meanings are generally privileged.

\section{Method}

Materials. The experiments required that we identify dominant and subordinate meanings for eponymous verb phrases. To collect

\section{Table 2}

Sample Stories and Paraphrases From Experiment 1

\section{Dominant Story Context}

Greg had injected the rats weeks before, and now ran some blood tests.

He carefully considered his results before becoming too excited. His partner Joseph thought they had just found a cure for AIDS. Joseph shouted, "You've done an Albert Einstein!"

Subordinate Story Context

Greg dozed off in the barber's chair, and woke up after getting his hair cut.

Greg was shocked at the terrible job that had been done.

The next day his friend Joseph commented how terrible he looked. Joseph shouted, "You've done an Albert Einstein!"

Joseph feels that Greg has accomplished a scientific milestone. [Dominant paraphrase]

Joseph feels that Greg has unkempt hair. [Subordinate paraphrase]

Dominant Story Context

Rick and his sister had found some old 70's records in the attic.

They put one on the player and laughed while they listened.

Then Rick began to move in time to the music.

He announced, "Watch me do a John Travolta."

Subordinate Story Context

Rick was once the most valuable player on his soccer team.

A drug habit had affected his skills, and he was removed from the team

Now he was in rehab, hoping to kick his habit and return to the sport. He announced, "Watch me do a John Travolta."

Rick is going to try to disco dance. [Dominant paraphrase]

Rick is going to try to make a comeback. [Subordinate Paraphrase]

these norms, we asked 39 native English-speaking undergraduates from the State University of New York at Stony Brook to provide interpretations of a series of phrases such as do an Albert Einstein and do a Michael Jackson. They were given a questionnaire with 45 eponymous verb phrases. The instructions read, "Your task is to write down the three most likely meanings of each verb phrase. Pretend that you have just heard the phrase during a conversation. What would be some meanings that seem most natural to you?" We transcribed the full set of participants' responses and removed from further analysis eponymous verb phrases based on names not recognized by at least 30 (approximately $75 \%$ ) participants. After removing these eponyms, we were left with 37 phrases.

The two authors went through the lists of interpretations and aggregated them into categories of meanings. We jointly scored two eponymous verb phrases (do a Michael Jackson and do a Neil Armstrong) to establish criteria for category similarity. For example, we considered to set foot on the moon, jump up and down on the moon, and be the first to walk on some planet all tokens of the same category. To define proper norms for dominant and subordinate meanings, we consulted similar studies in the literature on lexical ambiguity (e.g., Onifer \& Swinney, 1981). We aspired to achieve an average response rate of $75 \%$ for dominant interpretations and $25 \%$ for subordinate interpretations. Overall, we came close: For the 28 phrases, the mean frequency of production for dominant interpretations was $72.43 \%$; the mean frequency for subordinate interpretations was $29.75 \%$. Note that the subordinate meanings were not obscure; they were just furnished less often.

With dominant and subordinate meanings in hand for 28 phrases, we next wrote stories that we intended to create biases toward those dominant and subordinate meanings. Each story provided a three sentence discourse context leading to a fourth sentence containing the eponymous verb phrase. The eponymous verb phrase sentence was identical for both the dominant and subordinate stories. We also wrote two paraphrase sentences for each eponymous verb. One paraphrase represented the dominant interpretation of the eponymous verb phrase; the other paraphrase represented the subordinate 
interpretation. Over the set of stimuli, the mean number of words for both the dominant and subordinate paraphrases was 7.95 words per sentence.

To pretest these stories, we asked 32 native English-speaking Stony Brook undergraduates to read one version of each story and to indicate the extent to which the paraphrase that we proffered was consistent with their understanding. There were four versions of each item (dominant vs. subordinate story context, dominant vs. subordinate test sentence). Using a Latin square design, we placed one of the four yersions of each item on one of four questionnaires; each participant read 28 stories, 7 of each type. The instructions read, "Using a scale rating from 1 to 9 , we would like you to tell us how accurate you think the sentence is in defining the novel verb phrase." The endpoints of the scale were labeled 1 (Not at all the meaning I thought of) and 9 (Exactly the meaning I thought of).

Mean agreement rates for the dominant and subordinate story contexts for each paraphrase are presented in Table 3 . We were successful at creating contexts that differentiated the two meanings: Matching conditions (e.g., dominant story context with dominant paraphrase sentence and subordinate story context with subordinate paraphrase sentence) yielded higher agreement ratings than did nonmatching conditions. To provide statistical support for this interaction we performed analyses with both subjects $\left(F_{1}\right)$ and items $\left(F_{2}\right)$ as random variables $\left[F_{\mathrm{l}}(1,28)=224.04, M S_{\mathrm{e}}=2.30, p<.001\right.$; $\left.F_{2}(1,24)=183.66, M S_{\mathrm{e}}=2.453, p<.001\right]$.

Participants also gave higher accuracy ratings to dominant paraphrases $(M=5.24)$ than to subordinate paraphrases $(M=4.52)$ $\left[F_{1}(1,28)=54.07, M S_{\mathrm{e}}=.304, p<.001 ; F_{2}(1,24)=7.195, M S_{\mathrm{e}}=\right.$ $1.998, p<.025]$. This result suggests that the acts captured by the dominant meanings are more salient for the eponyms than those captured by the subordinate meanings. There was a main effect of context for subjects but not items $\left[F_{1}(1,28)=4.861, M S_{\mathrm{e}}=.598, p<\right.$ $\left..05 ; F_{2}(1,24)=3.024, M S_{\mathrm{e}}=.841, p>.05\right]$. On the basis of the data from this norming study, we selected the 20 eponyms that provided the best separation between dominant and subordinate contexts.

Although our intent was to create stories that provide strong biases toward the dominant or subordinate readings, it is appropriate to wonder to what extent the verb phrases themselves contribute to these biases. For example, what role does the phrase do a John Travolta play in fostering readers' belief that "to disco dance" is the meaning intended in the dominant story context? To address this question, we repeated this norming study but replaced the famous names with nonfamous (i.e., invented) names such as do a Todd Shanower. ${ }^{1}$ Aside from the change from famous to nonfamous names, the 48 participants performed the same task as in the norming study. Their ratings are given in Table 4 along with the original data for the subset of 20 famous eponyms. Note that the major difference between the famous and nonfamous names is found in the matching cells (e.g., dominant context and dominant test sentence) The presence of the famous name adds, on the average, about .905 points to the "accuracy" ratings in those cells but only .065 points to the ratings in the mismatched cells. When the data from the "famous" and "nonfamous" ratings were entered into a single analysis of variance, this observation was supported by a three-way interaction of fame, context, and test sentence $\left[F_{1}(1,78)=5.749, M S_{\mathrm{e}}=\right.$ $\left.2.461, p=.019 ; F_{2}(1,19)=12.242, M S_{\mathrm{e}}=0.564, p=.002\right]$. The irrelevance of the eponym in the nonmatching cells supports our be-

Table 3

Mean Agreement Rates for Story Context by Paraphrase Sentence in Norming Study

\begin{tabular}{lccc}
\hline & $\begin{array}{c}\text { Dominant } \\
\text { Paraphrase }\end{array}$ & $\begin{array}{c}\text { Subordinate } \\
\text { Paraphrase }\end{array}$ & $M$ \\
\hline Dominant story context & 7.40 & 2.67 & 5.03 \\
Subordinate story context & 3.09 & 6.38 & 4.73 \\
$M$ & 5.24 & 4.52 & \\
\hline
\end{tabular}

Table 4

Mean Agreement Rates for Famous and Nonfamous Names in Norming Study

\begin{tabular}{lccc}
\hline & $\begin{array}{c}\text { Dominant } \\
\text { Paraphrase }\end{array}$ & $\begin{array}{c}\text { Subordinate } \\
\text { Paraphrase }\end{array}$ & $M$ \\
\hline Famous Names & & & \\
$\quad$ Dominant story context & 7.50 & 2.04 & 4.77 \\
Subordinate story context & 2.32 & 6.64 & 4.48 \\
$M$ & 4.91 & 4.34 & \\
Nonfamous Names & & & \\
$\quad$ Dominant story context & 6.42 & 2.13 & 4.27 \\
Subordinate story context & 2.10 & 5.91 & 4.00 \\
$M$ & 4.26 & 4.02 & \\
\hline
\end{tabular}

Note-These ratings are for the 20 eponyms that provided the best separation between dominant and subordinate contexts.

lief that those contexts provided little or no support for the unintended meaning.

These control data suggest that, although the eponyms reinforce the biases, the contexts themselves go a long way toward establishing those biases. With respect to our major hypothesis, this is a desirable outcome. Our most important prediction is that, during moment-by-moment comprehension, dominant meanings will be active in subordinate contexts. We believe that the norming data with both famous and nonfamous names strongly indicate that this result could not emerge as an artifact of inadequacies in our biasing contexts. These norming studies provided us with the materials to pursue the more theoretically oriented goals of the project.

Participants. Twenty Stony Brook undergraduates participated in this study for class credit. All participants were native speakers of English.

Apparatus. The experiment was run on two IBM-compatible 486 personal computers that recorded reading times and agreement responses. Participants were seated in front of a MicroScan color monitor with their hands resting on the keyboard. They used buttons on the keyboard to make appropriate responses. The sentences were displayed in the center of the screen in standard upper- and lowercase type.

Design. The stories and paraphrase sentences for the phrases were the same as those used in our manipulation check. There were four versions of each item based on the 20 eponyms, as a function of story context and paraphrase sentence (see Table 2). Using a Latin square design, we constructed four lists of stories so that each story appeared in a different version on each list. Participants each read one list of 20 stories in random order.

Procedure. Participants began with five practice stories and paraphrases to become acquainted with the stimuli format and keyboard controls. Each story began with the words "Press NEXT for the next story" appearing on the monitor. Participants pressed the " $Y$ " key, labeled NEXT, to proceed to the next story. The first sentence of a story appeared on the screen. After reading it, participants pressed the spacebar to advance to the next sentence. This sequence was repeated for each of the four sentences. When participants pressed the spacebar after the fourth sentence, a beep sounded from the computer, and a paraphrase sentence appeared. Participants then were required to press either a YES (i.e., "I agree"; "/") or NO (i.e., "I disagree"; " $Z$ ") key in response to the paraphrase.

\section{Results and Discussion}

Only reading and paraphrase judgment times for stories on which participants made correct judgments were used in the analyses. We eliminated data falling three standard deviations above the mean. This resulted in a loss of $3.25 \%$ of the data. 
Table 5

Mean Response Latencies (in Seconds) and Percent Errors for Story Context $\times$ Paraphrase Sentence in Experiment 1

\begin{tabular}{|c|c|c|c|c|c|c|}
\hline & \multicolumn{2}{|c|}{$\begin{array}{l}\text { Dominant } \\
\text { Paraphrase }\end{array}$} & \multicolumn{2}{|c|}{$\begin{array}{l}\text { Subordinate } \\
\text { Paraphrase }\end{array}$} & \multicolumn{2}{|c|}{$M$} \\
\hline & $M$ & $\mathrm{PE}$ & $M$ & PE & $M$ & PE \\
\hline Dominant story context & 3.099 & 13.4 & 2.656 & 5.0 & 2.877 & 9.2 \\
\hline Subordinate story context & 3.027 & 9.2 & 2.967 & 12.9 & 2.997 & 11.0 \\
\hline$M$ & 3.063 & 11.3 & 2.811 & 8.9 & & \\
\hline
\end{tabular}

Participants took an average of $2.542 \mathrm{sec}$ to comprehend the eponymous verb phrase sentence in dominant contexts and $2.866 \mathrm{sec}$ to comprehend the sentences in subordinate contexts $\left[F_{1}(1,16)=14.981, M S_{\mathrm{e}}=175,308\right.$, $\left.p<.01 ; F_{2}(1,16)=19.085, M S_{\mathrm{e}}=113,104, p<.001\right]$. This result suggests that the dominant meanings were more accessible, although it also could reflect differences between the two types of context stories.

Mean paraphrase judgment times and error rates for the dominant and subordinate story contexts for each paraphrase are presented in Table 5 . Because we had separate expectations for "agree" and "disagree" responses, we used orthogonal contrasts to assess our predictions. We predicted, first, that the "agree" responses would show no differences across the contexts. In fact, the 132-msec difference was not reliable (both $F \mathbf{s}<1$ ). Conversely, the data support the second prediction that participants would find it relatively difficult to rule out dominant readings in subordinate contexts. This $371-\mathrm{msec}$ difference was reliable $\left[F_{1}(1,16)=4.57, M S_{\mathrm{e}}=300,981, p<.05 ; F_{2}(1,16)=5.24\right.$, $\left.M S_{\mathrm{e}}=315,766, p<.05\right]$. We take this difference as strong evidence that the dominant reading became accessible to some extent even when the context was strongly biased toward the subordinate readings. No other reliable effects emerged in the analyses of paraphrase judgment times.

One unexpected aspect of the data was that "yes" responses (i.e., responses in which the context and the paraphrase matched) were relatively slow (i.e., "yes" responses were on the average $195 \mathrm{msec}$ slower than "no" responses). Because the same pattern occurred in Experiment 2, we will delay comment until the General Discussion.

Analyses of the error rates revealed marginal significance for the interaction of context and paraphrase $\left[F_{1}(1,16)\right.$ $=3.732, M S_{\mathrm{e}}=0.018, p=.071 ; F_{2}(1,16)=1.994, M S_{\mathrm{e}}=$ $0.037, p>.10]$. Participants appeared to have experienced somewhat less difficulty in the nonmatching conditions (e.g., when a dominant interpretation was proffered for the subordinate context). No other effects emerged in the error analyses.

These results provide evidence for our hypothesis that dominant meanings are called to mind irrespective of context. We see an important parallel here, in this instance of sense creation, with results for circumstances of sense selection. That is, the dominant meanings of bank and do an Albert Einstein enjoy the same privilege across contexts.

\section{EXPERIMENT 2}

The privilege that dominant meanings enjoy for ordinary lexical ambiguities fades rather rapidly: As we discussed in the introduction, when meaning access is tested after brief intervals, the dominant meaning of an ambiguity typically fades away in subordinate contexts. We intended Experiment 2 to demonstrate a similar effect of delay for our eponymous verb phrases. We created a delay by adding an extra sentence into our stories. As shown in Table 6 , a neutral sentence intervened between the verb phrase and the paraphrase judgment. We predicted that this brief delay would allow the dominant meaning to fade in the mismatched context. Thus, we expected to see symmetrical effects of the match or mismatch between context and paraphrase.

\section{Method}

Participants. Twenty-eight Stony Brook undergraduates participated in this study for class credit. All participants were native speakers of English.

Apparatus. The apparatus was identical to that used in Experiment 1 .

Materials and Design. The stories and paraphrase sentences for the 20 eponymous verb phrases were the same as those used in Experiment 1 , except that we added a neutral final sentence to each story to delay presentation of the paraphrase sentence. The neutral sentences were identical for the dominant and subordinate biasing contexts.

As before, there were four versions of each item based on the 20 eponyms, as a function of story context and paraphrase sentence (see

Table 6

Sample Stories and Paraphrases From Experiment 2

Dominant Story Context

Arthur and Carl were watching a couple making out on a park bench. They were really going at it, even though it was a public place.

Arthur asked, "What's he doing to her now?"

Carl said, "I think he's trying to do a Dracula."

They had to stifle their laughs, for fear of being too loud.

Subordinate Story Context

Carl warned his friend Arthur to be quiet when he came up to the room. He explained that his roommate was still asleep.

Arthur asked, "Why is he in bed at two in the afternoon?"

Carl said, "I think he's trying to do a Dracula."

They had to stifle their laughs, for fear of being too loud.

Carl thinks the guy is trying to bite his girlfriend's neck. [Dominant paraphrase]

Carl thinks the guy is going to sleep all day. [Subordinate paraphrase]

Dominant Story Context

Jane's father was helping her with her batting stance.

She was becoming a more and more powerful hitter.

Even though she was a girl, she wanted to play Little League.

She told her dad, "I'm doing a Babe Ruth."

Her father told her, "No matter what, I'm proud of you."

Subordinate Story Context

Jane really wished she hadn't had dessert the night before.

Her favorite pair of pants was already getting too tight.

Her father came into the room and caught her staring in the mirror. She told her dad, "I'm doing a Babe Ruth."

Her father told her, "No matter what, I'm proud of you."

Jane thinks she's becoming a great baseball player. [Dominant paraphrase] Jane thinks she's becoming fat. [Subordinate paraphrase] 
Table 6). The four versions of each item were distributed to four presentation lists in a Latin square design. Each participant read one version of each story in random order.

Procedure. The procedure was identical to that of Experiment 1.

\section{Results and Discussion}

As in Experiment 1, only response times for stories on which participants made correct judgments were used. We eliminated response times falling more than three standard deviations above the mean. This resulted in a loss of $1.96 \%$ of the data.

Participants took an average of $2.382 \mathrm{sec}$ to comprehend the eponymous verb phrase sentences in dominant contexts and $2.672 \mathrm{sec}$ to comprehend the same sentences in subordinate contexts $\left[F_{1}(1,16)=14.598, M S_{\mathrm{e}}=97,000\right.$, $\left.p<.01 ; F_{2}(1,16)=15.021, M S_{\mathrm{e}}=87,706, p<.01\right]$. This result replicates the results for accessibility of dominant meanings in Experiment 1.

Mean reaction times and error rates for the dominant and subordinate story contexts are presented in Table 7 for each paraphrase. We predicted that the delay would eliminate the disadvantage for dominant readings in subordinate contexts. As is shown in Table 7, the delay prompted a nearly symmetrical pattern for the match and mismatch of context and paraphrase $\left[F_{1}(1,24)=8.362, M S_{\mathrm{e}}=418,530\right.$, $\left.p<.01 ; F_{2}(1,16)=4.248, M S_{\mathrm{e}}=339,024, p=.056\right]$. In Experiment 1 , participants took $371 \mathrm{msec}$ longer to say "no" to the dominant paraphrase in the subordinate context than they took to say "no" to the subordinate paraphrase in the dominant context. In Experiment 2, this difference was $7 \mathrm{msec}$. No other effects emerged in this analysis.

The error analyses showed a significant difference for dominant as opposed to subordinate test sentences $\left[F_{1}(1,24)\right.$ $=14.990, M S_{\mathrm{e}}=0.014, p<.01 ; F_{2}(1,16)=6.573, M S_{\mathrm{e}}=$ $0.022, p<.05]$. That is, participants made more errors when they were offered the dominant paraphrase, irrespective of context. This result reflects a particularly high error rate for dominant meanings in the subordinate contexts (compare the 9.2\% error rate in Experiment 1 and the $18.2 \%$ error rate in Experiment 2). This result weakens, to a certain extent, our claim that the privilege of dominance fades rapidly. There may, in fact, have been a tradeoff operating in this experiment that equalized judgment times at the expense of accurate performance. Even so, the result supports the more important general claim that meaning dominance wields an influence as much for eponymous verb phrases as for ordinary lexical ambiguities.

Table 7

Mean Response Latencies (in Seconds) and Percent Errors for Story Context $\times$ Paraphrase Sentence in Experiment 2

\begin{tabular}{|c|c|c|c|c|c|c|}
\hline & \multicolumn{2}{|c|}{$\begin{array}{l}\text { Dominant } \\
\text { Paraphrase }\end{array}$} & \multicolumn{2}{|c|}{$\begin{array}{c}\text { Subordinate } \\
\text { Paraphrase } \\
\end{array}$} & \multicolumn{2}{|c|}{$M$} \\
\hline & $M$ & $\mathrm{PE}$ & $M$ & $\mathrm{PE}$ & $M$ & $\mathrm{PE}$ \\
\hline Dominant story context & 2.916 & 15.2 & 2.676 & 6.5 & 2.796 & 10.9 \\
\hline Subordinate story context & 2.683 & 18.2 & 3.146 & 8.2 & 2.914 & 13.2 \\
\hline$M$ & 2.799 & 16.7 & 2.911 & 7.4 & & \\
\hline
\end{tabular}

\section{GENERAL DISCUSSION}

The purpose of these experiments was to demonstrate the generality of privilege for dominant interpretations of ambiguities. Our prediction was grounded in past research with ordinary lexical ambiguities showing that dominant interpretations are more accessible than subordinate interpretations (e.g., Tabossi \& Zardon, 1993). (Note, however, that dominant interpretations are not inevitably more accessible; see Simpson \& Krueger, 1991.) We have extended the result of greater accessibility for dominant interpretations of lexical ambiguities to dominant interpretations of eponymous verb phrases. Experiment 1 demonstrated that readers have relative difficulty ruling out the dominant paraphrases even in the subordinate contexts. Experiment 2 provided evidence that, with a delay, the dominant meaning interfered less with paraphrase judgments in the subordinate context. We take this pattern of data to support our major hypothesis that dominance effects emerge from memory processes that are not special to sense selection.

One aspect of our data that bears comment is the result in both experiments that "yes" responses took longer than "no" responses. That is, participants took considerable time to agree with the correct paraphrases. We believe that there are two possible explanations for this finding. It is possible, first, that the biasing contexts were just not appropriately effective. We are reluctant, however, to accept this explanation, because the results of our norming studieswhich tested the contexts-were reasonably definitive. The second explanation is that our paraphrase sentences may not have captured the meanings of the eponymous verb phrases with sufficient fidelity. We wonder, in fact, whether it is entirely possible to write paraphrases that will accurately capture the meanings of contextual expressions for all readers. We are suggesting, that is, that instances of sense creation may necessarily lead to less certainty in "yes" paraphrase judgments than do instances of sense selection. Whatever the truth of this speculation, it is important to notice that our critical predictions are framed with respect to "no" responses. Except for the predicted difficulty in Experiment 1 for the dominant test in the subordinate context, readers found it quite easy to rule out mismatched paraphrases.

We also acknowledge that our task — paraphrase judgment time-is quite different from the tasks used in the research from which we drew our predictions. That is, we did not use a task, such as cross-modal lexical decision or Stroop interference, that would allow us to track the moment-by-moment waxing and waning of meaning. We chose not to use these other types of tasks because we were not at all certain how to encapsulate interpretations of the eponymous verb phrases in single words. Although our methodology does not allow us to make highly specific time course claims, we believe that the pattern of results argues strongly that the dominant interpretations were accessible early on for the subordinate contexts. 
To put our results in a broader context, we return to the putative distinction between sense selection and sense creation. Our experiments suggest that a pattern of results that has been ascribed to processes of sense selection emerges vividly for one type of sense creation. Accordingly, we believe that our data argue against treating instances of sense selection and sense creation as a strict dichotomy: It may be rare, that is, to find cases in which the comprehension of words or phrases does not rely on both processes of selection and creation. Consider, the use of tomato in a variety of contexts (Johnson-Laird, 1975):

She sat on a tomato.

She likes tomato.

Her face was like a tomato.

Although the same general sense for tomato must be selected in each case, we might expect creation processes to adjust the ultimate representation, depending on context. For the eponymous verb phrases we used in our experiments, we also see a selection process, but it is a selection of information beyond the lexicon from more general longterm memory. Long-term memory provides the raw material which is then shaped by the creation processes that embody the effects of discourse context. The study of sense creation weakens faith in the existence-or necessity- of fully formed "entries" in a mental lexicon: We find a blurring of the distinction between dictionary and encyclopedia (Gerrig, 1986).

What we are suggesting, in summary, is that the distinction between sense selection and sense creation is both useful and misleading. This distinction is useful because it makes plain that not all - and, perhaps, very few-instances of meaning recovery constitute circumstances in which meanings can be selected ready-made from the mental lexicon. However, this distinction may be misleading, because it suggests that the processes of "selection" and "creation" apply to different categories of words or phrases-for example, ordinary lexical items versus contextual expressions. Our results support the contention that the form of a phrase does not specify what types of processes are required for ultimate understanding: We suggest that "selection" and "creation" operate quite broadly in the full range of instances of comprehension.

\section{REFERENCES}

Clark, E. V., \& Clark, H. H. (1979). When nouns surface as verbs. Language, 55, 767-811.

Clark, H. H. (1983). Making sense of nonce sense. In G. B. Flores d'Arcais \& R. Jarvella (Eds.), The process of understanding language (pp. 297-331). New York: Wiley.

ClaRK, H. H. (1997). Dogmas of understanding. Discourse Processes, 23, 567-598.

Clark, H. H., \& Gerrig, R. J. (1983). Understanding old words with new meanings. Journal of Verbal Learning \& Verbal Behavior, 22, $591-608$.

GAGNÉ, C. L., \& SHOBEN, E. J. (1997). Influence of thematic relations on the comprehension of modifier-noun combinations. Journal of Experimental Psychology: Learning, Memory, \& Cognition, 23, 7187.

GERRIG, R. J. (1986). Process and products of lexical access. Language \& Cognitive Processes, 1, 187-195.

GERRIG, R. J. (1989). The time course of sense creation. Memory \& Cognition, 17, 194-207.

Gerrig, R. J., \& MurPhy, G. L. (1992). Contextual influences on the comprehension of complex concepts. Language \& Cognitive Processes, 7, 205-230.

JoHNSON-LAIRD, P. N. (1975). Meaning and the mental lexicon. In A. Kennedy \& A. Wilkes (Eds.), Studies in long term memory (pp. 123-142). London: Wiley.

ONIFER, W., \& SWINNEY, D. A. (1981). Accessing lexical ambiguities during sentence comprehension: Effects of frequency of meaning and contextual bias. Memory \& Cognition, 9, 225-236.

Paul, S. T., Kellas, G., Martin, M., \& Clark, M. B. (1991). Influence of contextual features on the activation of ambiguous word meanings. Journal of Experimental Psychology: Learning, Memory, \& Cognition, 18, 703-717.

Simpson, G. B. (1994). Context and the processing of ambiguous words. In M. A. Gernsbacher (Ed.), Handbook of psycholinguistics (pp. 359374). San Diego: Academic Press.

Simpson, G. B., \& Krueger, M. A. (1991). Selective access of homograph meanings in sentence context. Journal of Memory \& Language, 30, 627-643.

TABOSSI, P., \& ZARDON, F. (1993). Processing ambiguous words in context. Journal of Memory \& Language, 32, 359-372.

WisNiewsKi, E. J. (1997). When concepts combine. Psychonomic Bulletin \& Review, 4, 167-183.

Zelinski, E. M., \& Hyde, J. C. (1996). Old words, new meanings: Aging and sense creation. Journal of Memory \& Language, 25, 689707.

\section{NOTE}

1. We thank Greg Simpson for suggesting this control.

(Manuscript received September 9, 1997; revision accepted for publication July 5, 1998.) 